\title{
Gallbladder Mixed Adenoneuroendocrine Carcinoma
}

National Cancer Institute

\section{Source}

National Cancer Institute. Gallbladder Mixed Adenoneuroendocrine Carcinoma. NCI

Thesaurus. Code C96927.

A carcinoma that arises from the gallbladder and is characterized by the presence of a

malignant glandular epithelial component and a malignant neuroendocrine component.

At least 30 percent of either component should be present for the diagnosis to be made. 